\title{
Reverse Migration Determinant Factor: A systematic literature review
}

\author{
Azreen Anuar ${ }^{1}$, Nur Huzeima Mohd Hussain ${ }^{2}$, Thuraiya Mohd², \\ Suraya Masrom ${ }^{3}$, Hugh Byrd ${ }^{4}$ \\ ${ }^{1}$ Centre of Graduate Studies, Universiti Teknologi MARA Perak Branch, Seri Iskandar Campus, Malaysia \\ 2 Department of Built Environment and Technology, \\ Universiti Teknologi MARA Perak Branch, Seri Iskandar Campus, Malaysia \\ ${ }^{3}$ Faculty of Computer and Mathematical Sciences Universiti Teknologi MARA Perak Branch, Tapah Campus Malaysia \\ ${ }^{4}$ Lincoln School of Architecture, University of Lincoln, Lincoln, United Kingdom \\ azreenanuar0309@gmail.com, nurhu154@uitm.edu.my, hura231@uitm.edu.my, \\ suray078@uitm.edu.my, hbyrd@lincoln.ac.uk \\ Tel: 018-9404361
}

\begin{abstract}
Reverse migration in Malaysia is a relatively new emerging phenomenon where the migrants have intentionally chosen to return to their hometown for better living. Thus, there is a demand to investigate the determinants that lead to these changing population mobility trends in Malaysia. This study adopts the systematic literature review to identify the determinant factors of reverse migration. The aim is to analyse empirical studies to determine factors in reverse migration. Consequently, the findings have revealed several determinants: following family, career, environment, economic reason, quality of life, and social aspect as the driving factors towards achieving subsistence living.
\end{abstract}

Keywords: reverse migration, systematic literature review, determinant, Malaysia

eISSN: 2398-4287@ 2021. The Authors. Published for AMER ABRA cE-Bs by e-International Publishing House, Ltd., UK. This is an open access article under the CC BYNC-ND license (http://creativecommons.org/licenses/by-nc-nd/4.0/). Peer-review under responsibility of AMER (Association of Malaysian Environment-Behaviour Researchers), ABRA (Association of Behavioural Researchers on Asians/Africans/Arabians) and CE-Bs (Centre for Environment-Behaviour Studies), Faculty of Architecture, Planning \& Surveying, Universiti Teknologi MARA, Malaysia.

DOI: https://doi.org/10.21834/ebpj.v6i16.2731

\subsection{Introduction}

Together with oil and gas resources, industrialisation has magnified urbanisation in Malaysia within 30 years of development. Malaysia has been showing a positive growth towards industrialisation following independence in 1957 (Hussain \& Byrd, 2012). The attraction of urbanisation has led to the rural-to-urban migration and rapid urban development with a shift from $73 \%$ rural to $73 \%$ urban population. However, the current COVID-19 pandemic has changed the world abruptly, affecting humanity with a breath-taking speed. This situation has led to migrant workers returning to native places in COVID-19 (Singh et al.,2020). COVID-19 pandemic has critically disrupted the workforce. Migrants were forced to go back to their native villages to find warmth and sympathy (Parveen, 2020). Due to the recent phenomenon of the health pandemic that has caused a disturbance in economic growth and a decline in foreign investment, the urbanisation attraction has become economically insecure. The situation is threatening employment, the cost of living, and food supply, steering towards urban poverty. As the population keeps growing, the demand for resources, especially food, could lead to supplies' insufficiency and could result in resource insecurity, poverty, and crime in urban areas (Hussain, 2015). The concern is whether the

eISSN: 2398-42870 2021. The Authors. Published for AMER ABRA cE-Bs by e-International Publishing House, Ltd., UK. This is an open access article under the CC BYNC-ND license (http://creativecommons.org/licenses/by-nc-nd/4.0). Peer-review under responsibility of AMER (Association of Malaysian Environment-Behaviou Researchers), ABRA (Association of Behavioural Researchers on Asians/Africans/Arabians) and CE-Bs (Centre for Environment-Behaviour Studies), Faculty of Architecture, Planning \& Surveying, Universiti Teknologi MARA, Malaysia.

DOI: https://doi.org/10.21834/ebpj.v6i16.2602 
urban society will remain in the city or do they have the options to move to remote places to make a living and improve well-being? Over time, the size and structure of migration flows have experienced substantial changes and caused long-term and short-term impacts on population size and structure (Titan et al., 2012). There is emerging evidence of changing trends in population mobility in Malaysia. Many researchers have highlighted reverse migration as an emerging phenomenon in this situation. This paper intends to investigate the factors that have influenced the migrants' decision in migrating back to rural areas that include (i) economy, (ii) career, and (iii) quality of life as significant motives or the reverse migration trends.

This study adds to the literature by focusing on the determinant factors in reverse migration. Numerous studies on the factors that have influenced migrants to return to rural areas, mainly following family (Crow, 2010; Cattaneo and Robinson, 2020; Mulder and Lundholm, 2020; Mohapatra and Jha, 2020; Space et al., 2014; Harrison, 2018; Ikegami \& Tsuruta, 2017; Hussain et al., 2017; Kanai, 2016; Farrell et al., 2012). Other scholars emphasize occupation, environment, economic reason, quality of life, and social aspect motivations as factors that could also influence migrants to migrate back to rural areas. The systematic literature review is generally seen as a comprehensive method of assessing a specific research topic (Tranfield et al., 2003). Therefore, a systematic literature review suits this paper's aim to analyse empirical studies and scholarly articles related to determinant factors in reverse migration. With Scopus and Google Scholar search engines' aid, this paper has shortlisted $n=13$ reviews out of the $n=340$ database discovered through the selection processes.

This paper is structured as follows. The first section introduces the research background, followed by the method and analysis of SLR. In the subsequent section, this paper discusses the method which is by using a systematic literature review. Finally, the findings of the systematic literature review are being emphasised, and the suggestion and recommendations for future studies are presented.

\subsection{Method using the Systematic Literature Review Structure}

A systematic literature review search was used to identify the factor that influenced the migrants to migrate back to rural areas. A systematic literature review is a comprehensive literature review that gathers and critically evaluates multiple research studies or articles (Cruz-Benito, 2016). The systematic literature review is vital because it provides a detailed and comprehensive review of related studies and encourages the development of new theories (Webster and Watson, 2002). Kitchenham (2004) has addressed that the systematic literature review is defined as a rigorous systematic way to identify, analyze and interpret an existing collection of studies on a topic or a phenomenon of interest.

In order to collect the secondary data, research studies, and synthesize findings quantitatively and qualitatively, a systematic literature review was applied (Rifkin, 2018). The researcher has reviewed the literature on fundamental determinant factors and reverse migration to seek factual studies conducted on the current date. The SLR methodology for determinant factors reverse migration is illustrated in the section below. Figure 1 presents the phases of the SLR method used in this study.

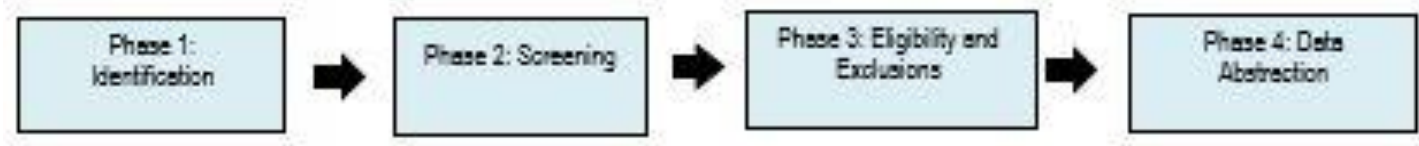

Fig 1: Four phases of the SLR system involved.

\subsection{Phase 1: Identification of Literature}

The investigation begins with a significant search in determinant factors related terms or topics related to the reverse migration was carried out by searching the question that does a systematic search through existing publication databases. This study has used Google Scholar and Scopus to identify literature reviews or search queries justified by the significant abstracts and citation databases of peerreviewed publications. Before registration with Scopus and access to https://login.ezaccess.library.uitm.edu.my/menu, the procedure for this systematic literature review can be obtained. For each database, keywords such as 'Factor' and 'Reverse Migration' were specified for the search terms and techniques used during the search process. The review has resulted in 340 pieces of literature identification with similar keywords mentioned earlier in this section. From 340 literature items, 294 items were omitted as these articles are not under the social sciences area, and the publication years range from the year 2020 up to the year 2010. Subsequently, only 46 pieces of the remaining literature items suit this paper's subject area and years of publication after this identification phase. The search string is summarised in Table 1.

Table 1: SLR Table Search String

\begin{tabular}{|c|c|}
\hline Database & Keywords \\
\hline Scopus & TITLE-ABS-KEY ("Factor") AND ("Reverse Migration") \\
\hline Google Scholar & ("Factor") AND ("Reverse Migration") \\
\hline
\end{tabular}

\subsection{Phase 2: Screening of the Identified Literature}

In the second phase, the search engine has identified 46 studies screened to match the context of the determinant factors of reverse migration. The screening was carried out by the elements of a subject area, social sciences, and years of publication taken from 2020 till 2010. The screening was done to exclude any literature duplicates (similar authors, similar research title). From 46 studies that were 
screened, two articles were omitted as these articles were duplicates due to having similar authors and similar research titles. Following the screening phase, 44 pieces of literature remained suitable for this paper's topic, I.e. the determinant factors in reverse migration.

\subsection{Phase 3: Eligibility and Exclusion}

The third phase was the eligibility and exclusion phase. In this phase, the remaining 44 literature items were thoroughly reviewed, and 31 full-text publications were omitted. From 31 articles that were excluded, 13 articles with no related topics and not in English were omitted as these articles do not contribute to research significantly. Meanwhile, the remaining 18 excluded articles are presented in Table 2, showing related references to the topics that do not contribute to the research determinant factors in reverse migration. Table 2 illustrates the list of publications related to this topic but did not significantly contribute to the research. Following the exclusion process, this study has highlighted 13 significant references to be included in SLR screenings. The selection of these inclusion articles is explained in Figure 2. In detail, Figure 2 shows a systematic flow chart of SLR from Subsection 2.1 until Subsection 2.3.

Table 2: Excluded Articles

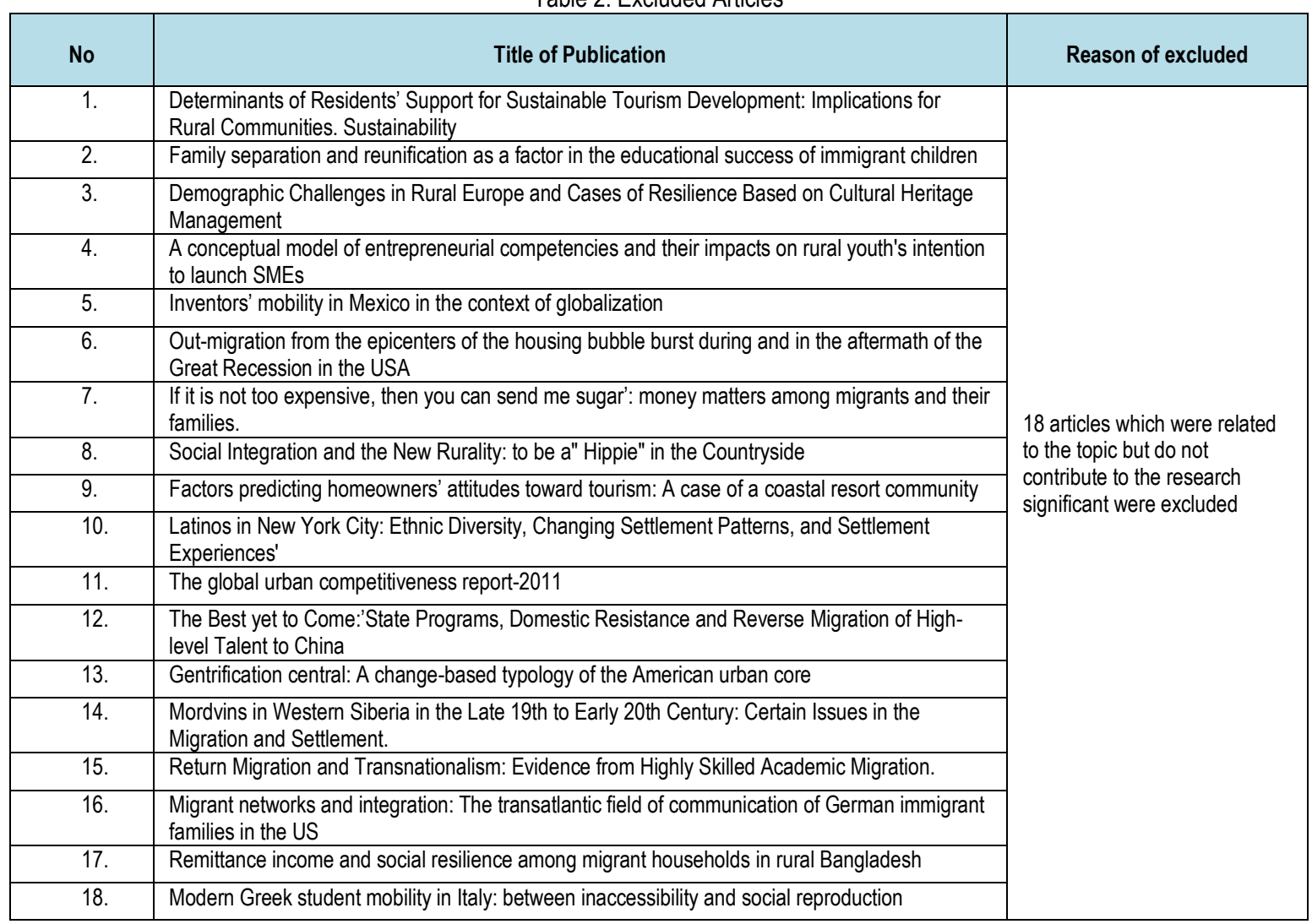

To better understand the determinant factors in reverse migration theories, this study has conducted a systematic literature review, and thirteen (13) articles were included and highlighted in Table 3. The data in Table 3 has been categorised into author(s), name of publication, year of publication, and country of study. After the eligibility phase, this phase was implemented and it focused only on the included issues because of a few factors. In the systematic literature review checklist, reverse migration determinant factors were categorised into ten (10) factors: family, career/occupation, environment, marriage, education, economic reason, quality of life, social aspect, safety, and health. Table 3 shows ten (10) factors with the frequency from previous literature that influences determinant factor in reverse migration is following family $(F=9)$, Marriage $(F=3)$, Education $(F=2)$, career/occupation $(F=10)$, quality of life $(F=6)$, environment $(F=5)$, economic reason $(F=4)$, Safety $(F=2)$, Health $(F=1)$ and social aspect $(F=4)$ 


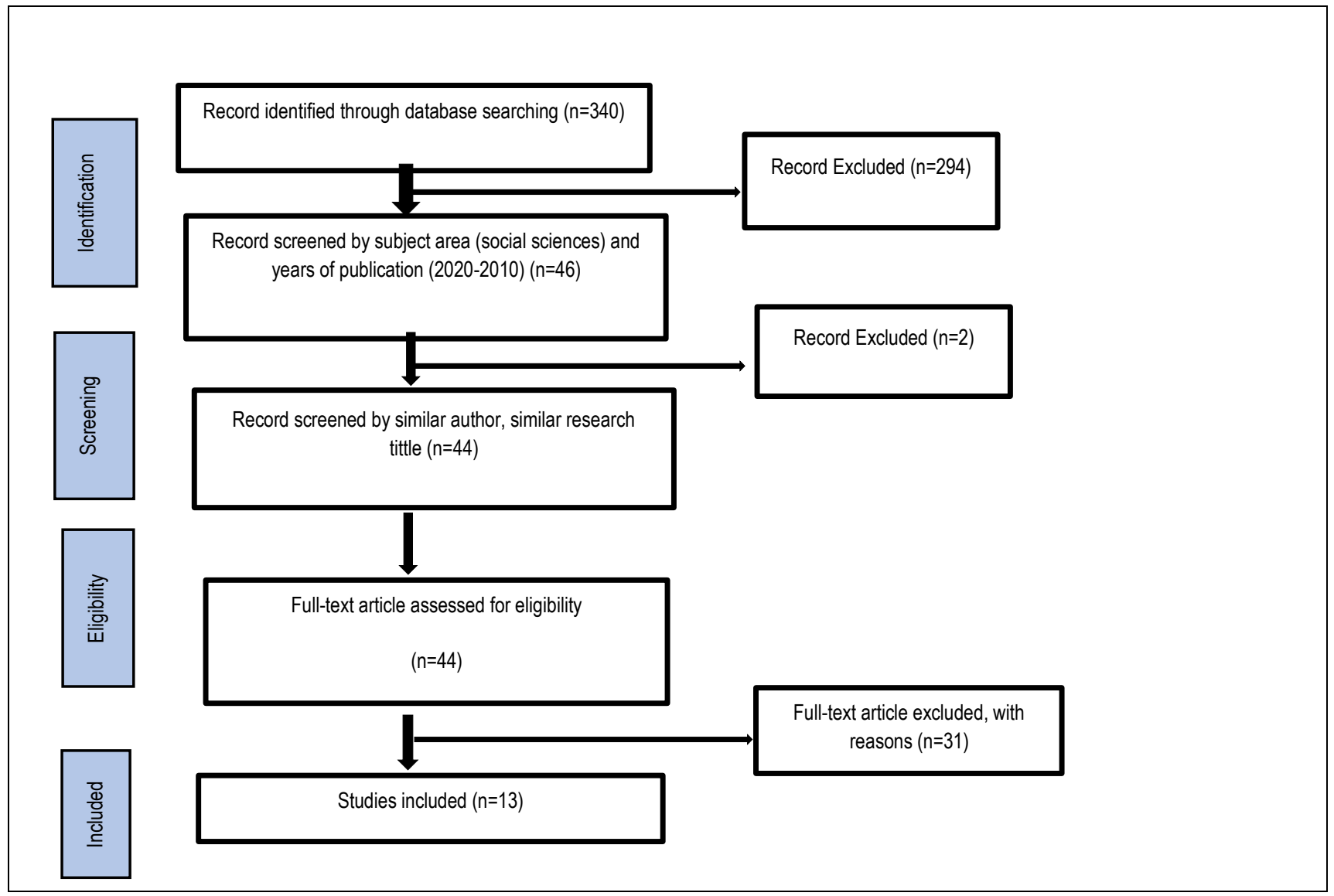

Fig 2: Systematic Review Flow Diagram

Table 3: Machine Learning Prediction for Reverse Migration Determinant Factor

\begin{tabular}{|c|c|c|c|c|c|c|c|c|c|c|c|c|c|c|c|}
\hline \multirow{4}{*}{ 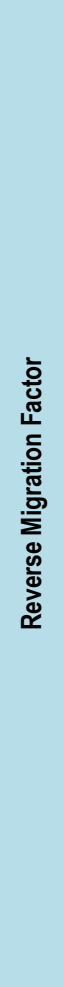 } & 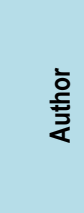 & 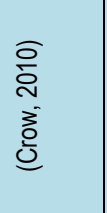 & 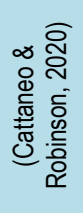 & 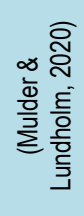 & 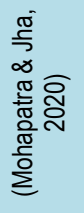 & 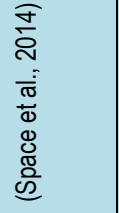 & 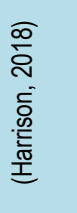 & 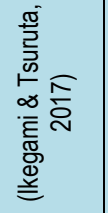 & 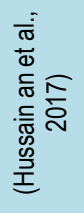 & 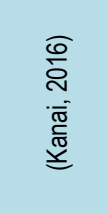 & 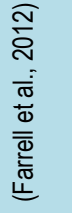 & 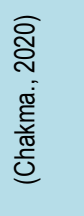 & 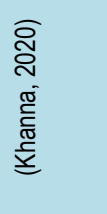 & 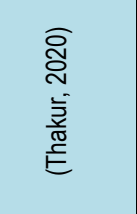 & \multirow{4}{*}{ 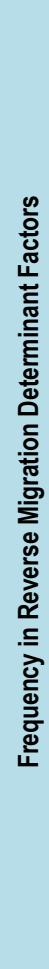 } \\
\hline & 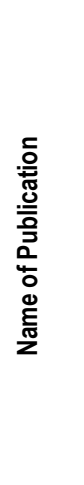 & 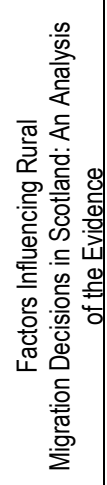 & 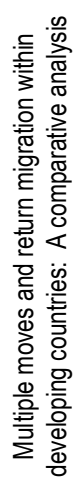 & 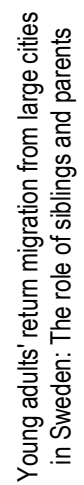 & 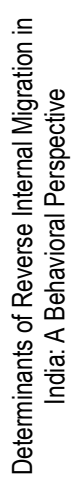 & 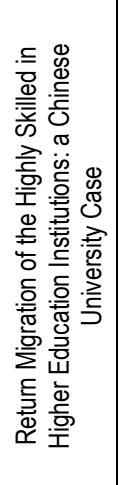 & 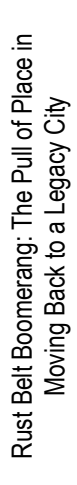 & 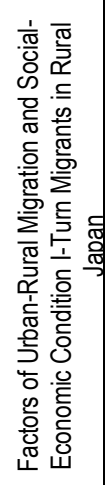 & 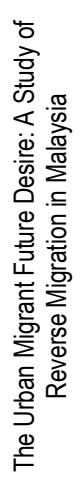 & 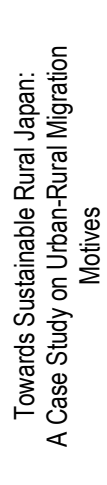 & 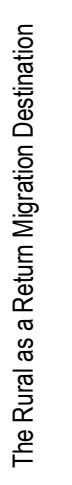 & 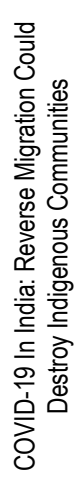 & 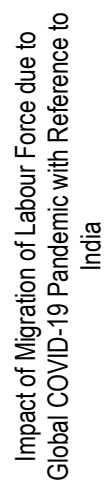 & 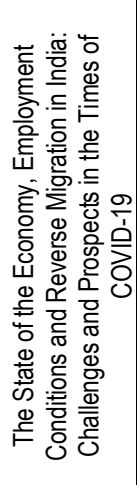 & \\
\hline & $\begin{array}{l}\text { Year } \\
\text { of } \\
\text { Public } \\
\text { ation }\end{array}$ & 2010 & 2020 & 2020 & 2019 & 2014 & 2017 & 2017 & 2017 & 2016 & 2011 & 2020 & 2020 & 2020 & \\
\hline & $\begin{array}{l}\text { Count } \\
\text { ry of } \\
\text { Study }\end{array}$ & $\begin{array}{l}\text { Scotla } \\
\text { nd }\end{array}$ & India & $\begin{array}{l}\text { Nethe } \\
\text { rlands }\end{array}$ & India & China & Ohio & Japan & $\begin{array}{l}\text { Malay } \\
\text { sia }\end{array}$ & Japan & $\begin{array}{l}\text { Irelan } \\
\text { d }\end{array}$ & India & India & India & \\
\hline & & & & & & & & & & & & & & & \\
\hline
\end{tabular}




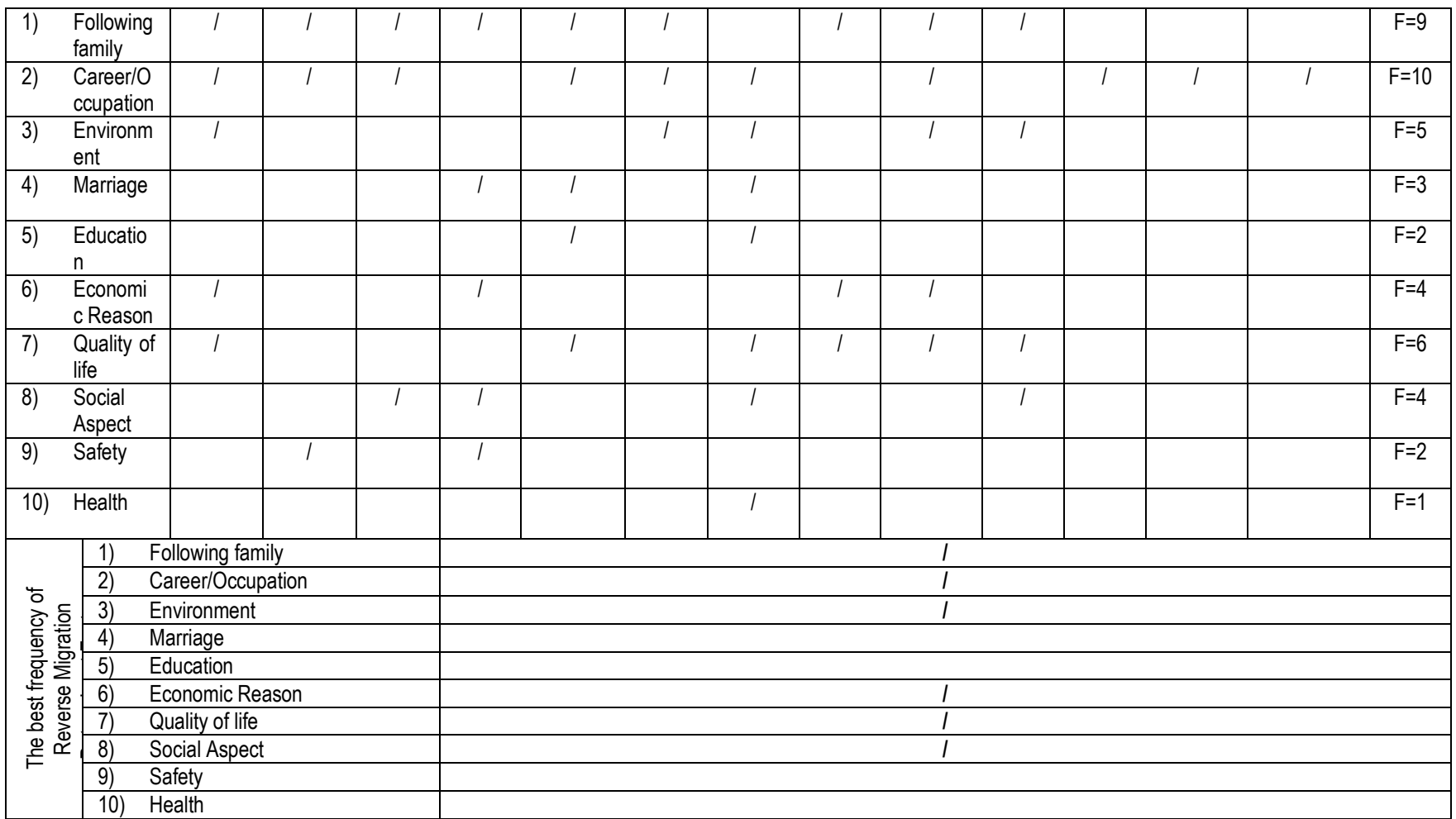

\subsection{Phase 4: Items Abstraction}

The final phase is the abstraction phase. In the abstraction phase, the frequency of reverse migration determinant factors was reduced from ten (10) to six (6) factors. The reduction was based on the highest frequency of reverse migration determinant factors obtained from the previous literature studies. This abstraction later formed the suggested reverse migration determinant factors, classified into six (6) factors. These factors are family, career/occupation, environment, economic reason, quality of life, and social aspect. Table 3 illustrates that the determinant factors in reverse migration from previous literature; they are as follows: family $(F=9)$, career/occupation $(F=10)$, quality of life $(F=6)$, environment $(F=5)$, economic reason $(F=4)$, and social aspect $(F=4)$. The simple justification for these factors is discussed in Section 3.

\subsection{The Suggested Determinant Factor in Reverse Migration}

After reviewing the studies carried out by other researchers, this article has gathered all the data to examine and identify the factors which other researchers most frequently use in determining reverse migration. These studies focused on collecting the determinant factor in reverse migration - the research method itself is based on four (4) criteria. The criteria were developed to include literature in the systematic review: (i) the literature had to focus on the thirteen (13) studies related to topics determinant factor in reverse migration and contribute to research significantly (ii) subject area such as social science, and literature review were published in scientific journals from 2010-2020 (iii) selected databases that established by Scopus and Google Scholar and were written in English and (iv) articles were omitted as the articles were found to be duplicates due to having similar authors and similar research tittles. The methods that were performed are identifying, screening, and assessing eligibility and extracting data. The study selection method is revealed in Figure 2. Based on the findings in Table 3, the recommended reverse migration determinant factors based on their frequencies are family, career/occupation, environment, economic reason, quality of life, and social aspect. Meanwhile, Section 3.1, 3.2, 3.3, 3.4, 3.5, and 3.6 explain in detail each of the suggested factors in the reverse migration aspect.

\subsection{Following Family}

First and foremost, return migrants listed their parents as the focal point of the return to move (Mulder \& Lundholm, 2020). This is supported by Hussain et al. (2017), where family reason was indicated as the main motivation in returning to the rural areas due to responsibility factor. Stepping into the last phase of life, parents want their children to have physical, financial, and emotional support. It has been found that parents whose children have migrated face a loss in enjoyment and an increase in loneliness level, resulting in depressive symptoms at mental health levels (Scheffe \& Zhang, 2019).

Migrant workers working in urban areas are conscious and aware of the responsibility to look after their parents in depressing situations. Migrants born and raised in rural areas still have their parents living in rural areas, which has become the critical factor that pulled them back to rural areas (Kanai, 2016). Therefore, many migrants leave urban areas to be with their parents in rural areas (Mohapatra \& Jha, 2019). 


\subsection{Career/Occupation}

Reverse migration can be caused by difficult conditions such as poor salaries, or unemployment (Mulder \& Lundholm, 2020). All commercial businesses have closed their operations due to the nationwide lockdown, resulting in unemployment and people returning to their hometowns or villages (Chakma, 2020). According to Al Jazeera (2020), as cited in Khanna, A. (2020), the lockdown during Covid-19 has caused tens of millions of migrant workers to be jobless in India by March 2020. Many migrant workers have returned to their families, and many more are waiting for the lifting of the lockdown. Awareness about local employment opportunities encourages and influences people's decisions to move into rural areas (Crow, 2010). According to Hussain et al. (2017), another factor of returning to rural areas is the economic potential offered by owning or inheriting properties in rural areas. Malaysia is unique in its land ownership legislation, where the Malay society cannot sell their land properties (Hussain \& Byrd, 2016; Leete, 2007). Urban migrants still own their land and houses in rural areas even though they have migrated to urban areas. They have the chance to return to their villages or kampungs once again and survive for their own life (Hussain et al., 2017). Thus, careers and occupations have become factors for people to leave urban areas and move to rural areas again.

\subsection{Environment}

Returnees/villagers found that it is necessary to live in an environment where appreciation, respect, and self-fulfilment still exist (Mohapatra \& Jha, 2019). According to Crow (2010), the natural environment's quality encourages people to move back to a rural area. They enjoyed rural life due to the following reasons, such as a comfortable lifestyle and rich natural surroundings (Ikegami \& Tsuruta, 2017). The concept of peace and calm influenced returnees' motivation to return, as did their decisions to leave to their friends and families (Farrell et al., 2012). Therefore, the environment is also a determinant factor for people to return to rural areas.

\subsection{Economic Factor}

According to Mohapatra (Mohapatra \& Jha, 2019), there is minimal or no income increment. On the other hand, expenditure is rising day by day because of inflation's overall impact, with higher rental prices, increasing water and electricity bills, rising food prices, etc. Thus, the rental houses become a distant dream for the people who are working as hawkers, laborers, and lower-middle-class people. In urban areas, 6 to 8 people share one room. Economic factors such as job opportunities, low housing prices, and social factors are linked to family needs and connections and are certainly influential for people to move back to rural areas (Harrison, 2018).

These differences in urban and rural cost life lead the poor in urban areas to be financially burdened. The lower cost of living in rural areas is a motivational factor as it attracts them to seek a better life quality, such as better housing or more children (Kanai, 2016). In general, monthly expenditures are low in rural areas, despite the family's size and composition and affordable prices of goods and quitting lavish urban lifestyles (Ikegami \& Tsuruta, 2017). This factor is very influential for people to return to rural areas.

\subsection{Quality of Life}

According to Crow (2010), accurate perception of the quality of life, access to outdoor activities and other activities for recreation, and a good sense of community are offered in rural areas. The potential of living in kampongs is seen differently by those who want to return to the kampongs. This is supported by Hussain et al. (2017) in their study where living in rural areas was described as more peaceful, clean, and healthy. The traditional rural views highlight a more positive quality of life associated with the natural environment, sense of good community support, and unity of rural areas (Farrell et al., 2012). Therefore, quality of life becomes an essential factor for people to move to rural from urban areas.

\subsection{Social Aspect.}

The reason why people move back to rural areas is the strong desire to raise their children in rural areas, as they believe that children who are raised in rural environments have better moral characters. Children are often seen as social assets where individual members of the community take up the responsibility collectively in growing and raising them. The children also are growing with less pressure compared to living in urban areas. (Ikegami \& Tsuruta, 2017). According to Kanai (2016), the decision to migrate is the social aspect and is based on subjective judgments. There is a "social pressure" factor that makes people compare themselves and family members continuously with others. These are subjective judgments of the place that consequently lead to stress among the city dwellers.

In comparison to their former experiences in the cities, they have closer relationships with people in rural areas. People in rural areas are closer to their neighbours because people in villages are more likely to cooperate with others in small village communities where it is simple to know each other. (Ikegami \& Tsuruta, 2017).

\subsection{Conclusion}

This paper presents a systematic literature review of factors that influenced the migrants' decision to migrate back to rural areas. This paper has adopted the systematic literature review (SLR) technique in assisting the selection of significant factors for reverse migration. The identification of related reviews from Scopus and Google Scholar searching engine explored n=340 databases, and 294 literature were omitted as these articles were not in the social sciences area and years publication from 2020 till 2010 . From 46 articles screened, 2 articles were omitted, followed by the screening phases, which discovered 44 number of literature items pursuing the determinant factors in reverse migration topics. However, 31 literature items were then excluded as; (i) 13 articles are not related to topics and are not written in English, (ii) the remaining 18 articles of the excluded articles were related to the topics but did not contribute to the research 
significance. Therefore, this SLR screening method has highlighted a number of 13 articles as significant and reliable references in determining the reverse migration factor in Malaysia. The outcome has led to identifying the six determinant factors in reverse migration for this analysis: family, career/occupation, environment, economic reason, quality of life, and social aspect. This paper recognizes systematic literature review as a reliable reviewing mechanism to assist other researchers. As for the recommendation, future research should explore additional motivations and issues that may influence urban to rural migration decisions of specific groups, such as women, those from different income groups, people from ethnic minority groups, and those with special needs. This study's findings must be seen together in light of some limitations where the sample size is limited to the keywords used in the systematic literature review process. The sample size is too small in order to make a general conclusion based on determinant factors in reverse migration. The sample size should be more significant in the amount to make a general conclusion on the determinant factor in reverse migration. Further research would help create a deeper understanding of decisions on urban to rural migration and forecast future trends and needs in population mobility. The return of migrants to rural areas provides an opportunity to transform land systems to become more resilient and sustainable. COVID-19-induced reverse migration will be a significant driver of land change in the upcoming years and need to account for land-use change studies.

\section{Paper Contribution to Related Field of Study}

This paper concerns the development of human resources that significantly impacts the government. The study on migration is relatively crucial for urban planning purposes. This is because migration is relevant to the development policy of urban planning. The related government policies including Local Agenda 21 (Quality of Life), Ministry of Housing \& Local Government, The Department of Urban and Rural Planning, Department Statistics Malaysia (DOSM), and Ministry of Rural Development. Generally, its relevance is referred to two aspects or issues contribution of migration on urban growth as well as the level of urbanisation, and the negative implications of migration on urban areas such as urban sprawl, squatters and slum areas, poverty, traffic congestion, and pollution. Therefore, population migration and mobility changes may affect the quality of life, land use, job opportunities, and many more. This paper is essential to develop significance in predicting future trends and needs in population mobility.

\section{Acknowledgement}

We would like to express our gratitude to the Research Management Institute (RMI), Universiti Teknologi MARA, for granting complete trust in us to conduct this research. Special thanks to our sponsors: MOHE-Fundamental Research Grant Scheme (FRGS), for providing an adequate provision, opportunity, and invaluable support throughout the research period. We hope that the idea shared in this paper will enrich the fundamental determination of reverse migration, specifically in the context of SLR application.

\section{References}

Cattaneo, A., \& Robinson, S. (2020). Multiple moves and return migration within developing countries: A comparative analysis. Population, Space and Place, e2335.

Chakma, D. (2020). COVID-19 in India: Reverse migration could destroy indigenous communities. Copenhagen: International Work Group for Indigenous Affairs.

Crow, H. (2010). Factors influencing rural migration decisions in Scotland: an analysis of the evidence. Scottish Government.

Cruz-Benito, J. (2016). Systematic literature review \& mapping.

Farrell, M., Mahon, M., \& mcdonagh, J. (2012). The rural as a return migration destination. European Countryside, 4(1), 31-44.

Harrison, J. A. (2017). Rust belt boomerang: The pull of place in moving back to a legacy city. City \& Community, 16(3), 263-283.

Hussain, N. H. M. \& Byrd, H. (2016), 'Balik Kampong': Is Malaysia Facing the Trends of De-Urbanization, International Journal of the Malay World and Civilisation ( Iman ) 4(Special Issue 2), 2016: 35 - 43

Hussain, N. H. M., \& Byrd, H. (2012). Towards a compatible landscape in Malaysia: An idea, challenge and imperatives. Procedia-Social and Behavioral Sciences, 35 275-283.

Hussain, N. H. M., Byrd, H., \& Ahmad, N. A. (2017). The Urban Migrant Future Desire: A Study Of Reverse Migration In Malaysia. Malaysian Journal of Sustainable Environment, 3(2), 177-192.

Kanai, L. (2016). Towards Sustainable Rural Japan: A Case Study on Urban-Rural Migration Motives.

Kitchenham, B. (2004), "Procedures for performing systematic reviews”, Keele, UK, Keele University, Vol. 33 No. 2004, pp. 1-26

Leete, R. (2007). Malaysia: From Kampung to Twin Towers: 50 years of Economic and Social Development. Kuala Lumpur: Oxford Fajar. Kuala Lumpur

Mohapatra, A. K., \& Jha, S. (2020). Determinants of Reverse Internal Migration in India : A Behavioural Perspective Determinants of Reverse Internal Migration in India : April. https://doi.org/10.13140/RG.2.2.11707.16166

Mulder, C. H., Lundholm, E., \& Malmberg, G. (2020). Young adults' return migration from large cities in Sweden: The role of siblings and parents. Population, Space and Place, 26(7), e2354. 
Munya, A., Hussain, N. H. M., \& Njuguna, M. B. (2015). Can devolution and rural capacity trigger de-urbanization? Case studies in Kenya and Malaysia respectively. GeoJournal, 80(3), 427-443

Obikwelu, F. E., Ikegami, K., \& Tsuruta, T. (2017). Factors of urban-rural migration and socio-economic condition of I-turn migrants in rural Japan. Journal of Asian Rural Studies, 1(1), 70-80.

Rifkin, D. I., Long, M. W., \& Perry, M. J. (2018). Climate change and sleep: A systematic review of the literature and conceptual framework. Sleep medicine reviews, 42 , 3-9.

Seema parveen, D. (2020). A Study On Reverse Migration Of Human Resources: A Study Of Uttarakhand State. PalArch's Journal of Archaeology of Egypt/Egyptology, 17(7), 8961-8975.

Scheffel, J., \& Zhang, Y. (2019). How does internal migration affect the emotional health of elderly parents left-behind?. Journal of Population Economics, 32(3), 953-980.

Singh, S. K., Vibhuti, P., Aditi, C., \& Nandlal, M. (2020). Reverse migration of labourers amidst COVID-19. Economic and Political Weekly, 25-29.

Space, P., Wang, Q., \& Tang, L. (2014). Return Migration of the Highly-Skilled in Higher Education Institutions: A Chinese University Case. January 2020. https://doi.org/10.1002/psp.1855 